\title{
SISTEMA INTERAMERICANO DE DIREITOS HUMANOS: PROTEÇÃO AO MEIO AMBIENTE
}

\section{THE INTER-AMERICAN SYSTEM OF HUMAN RIGHTS: ENVIRONMENTAL PROTECTION}

\author{
${ }^{1}$ Leila Bijos \\ ${ }^{2}$ Carmem Elisa Hessel
}

\section{RESUMO}

O objetivo do presente artigo é refletir acerca da interconexão entre o direito ao meio ambiente sadio e os direitos humanos no âmbito do Sistema Interamericano de Direitos Humanos, traçando-se um panorama a partir das diferentes formas de abordagem da temática ambiental na esfera dos casos analisados pela Comissão e Corte Interamericanas.

Palavras-Chave: Meio Ambiente; Sistema Interamericano de Direitos Humanos; Direitos Humanos; Convenção Americana sobre Direitos Humanos; Desenvolvimento sustentável.

\begin{abstract}
The main objective of this paper is to bring to the reflection the interconnection between the right to a healthy environment and human rights within the Inter-American System of Human Rights. The analysis presents a broad picture of the different forms of environmental thematic approach in the field of violations examined by the Commission and Inter-American Court.
\end{abstract}

Keywords: Environment; Inter-American System of Human Rights; Human rights; American Convention on Human Rights; Sustainable development.

\footnotetext{
${ }^{1}$ Pós-Doutora pela Saint Mary's University - SMU, Halifax (Canadá). Professora do Mestrado em Direito pela Universidade Católica de Brasília - UCB, Distrito Federal (Brasil). E-mail: leilabijos@gmail.com

${ }^{2}$ Mestre em Direito pela Universidade Católica de Brasília - UCB, Distrito Federal (Brasil). Procuradora da República - PRM, Porto Alegre/ RS. (Brasil).
} 


\section{INTRODUÇÃO}

O crescente movimento de globalização de iniciativas econômicas voltadas à instalação de grandes empreendimentos se faz presente na contemporaneidade, uma vez que para se constituírem, em determinadas regiões, acabam por afetar seriamente o meio ambiente e as condições de vida das populações locais, especialmente nas Américas, acarretando violações a direitos humanos passíveis de proteção perante o sistema internacional.

Nesse contexto, considera-se pertinente realizar-se uma reflexão acerca da interconexão entre o direito ao meio ambiente sadio e os direitos humanos no âmbito do Sistema Interamericano de Direitos Humanos, traçando-se um panorama a partir das diferentes formas de abordagem dos aspectos ambientais nos casos analisados na esfera da Comissão e Corte Interamericanas.

Para tanto, inicia-se o estudo com um breve histórico sobre como se constituiu a ideia de proteção internacional dos direitos humanos, com ênfase no papel das Nações Unidas e da Declaração de 1948. Prossegue-se com a análise do Sistema Interamericano de Direitos Humanos, examinado-se seus órgãos constitutivos (Comissão e Corte Interamericanas), suas características e regras de funcionamento.

Passa-se então ao estudo do meio ambiente sadio como direito humano, buscando situar-se a temática ambiental no contexto geral dos direitos humanos, tanto sob o aspecto histórico quanto legal e doutrinário, de forma a demonstrar-se a evolução de seu regime de proteção em âmbito internacional. A seguir, são expostos os instrumentos normativos aplicáveis e suas particularidades, a saber: a Convenção Interamericana de Direitos Humanos (Pacto de San José da Costa Rica), o Protocolo de San Salvador e a Declaração de Estocolmo.

Na sequência, procede-se à verificação dos mecanismos utilizados para proteção ao direito ao meio ambiente, através de sua vinculação aos direitos civis, políticos, econômicos, sociais e culturais, o que tem sido denominado de greening ou "esverdeamento" dos Sistemas regionais de direitos humanos. No item seguinte, busca-se examinar de forma concreta alguns precedentes relevantes apreciados no âmbito da Corte e da Comissão Interamericanas, em que se pode observar de que formas ocorreu a interconexão entre o direito ao meio ambiente e os direitos humanos cuja violação foi arguida perante o Sistema.

Por fim, a conclusão sintetiza os principais aspectos que foram objeto de análise neste estudo, a fim de possibilitar uma visão mais ampla acerca do tema relacionado à conexão entre o direito ao meio ambiente e os direitos humanos tratados pelo Sistema Interamericano e, 
assim, viabilizar a reflexão sobre possíveis avanços e soluções aos inúmeros desafios da matéria.

\section{BREVE HISTÓRICO SOBRE A PROTEÇÃO INTERNACIONAL DOS DIREITOS HUMANOS}

Até a fundação das Nações Unidas, em 1945, não era seguro afirmar que houvesse, em direito internacional público, preocupação consciente e organizada sobre o tema dos direitos humanos. De longa data alguns tratados avulsos cuidaram, incidentalmente, de proteger certas minorias dentro do contexto da sucessão de Estados. Usava-se, por igual, do termo intervenção humanitária para conceituar, sobretudo ao longo do século XIX, as incursões militares que determinadas potências entendiam de empreender em território alheio, à vista de tumultos internos, e a pretexto de proteger a vida e o patrimônio de seus nacionais que ali se encontrassem.

A Carta de São Francisco (26/06/1945), segundo Pierre Dupuy, fez dos direitos humanos um dos axiomas da nova organização, conferindo-lhes idealmente uma estatura constitucional no ordenamento do direito das gentes. Em seguida, em 10 de dezembro de 1948, a Assembleia Geral aclama a Declaração dos Direitos do Homem, que exprime as normas de direitos humanos e na qual as Convenções supervenientes encontram seus princípios e seus alicerces.

Na Declaração de 1948 constam normas relativas a direitos civis e políticos (direitos humanos de "primeira geração"), direitos econômicos, sociais e culturais (direitos humanos de "segunda geração"), direito à paz, ao meio ambiente, à copropriedade do patrimônio comum do gênero humano (direitos humanos de "terceira geração"). Cumpre salientar que o problema inerente a esses direitos de terceira geração é identificar seus credores e devedores no plano nacional e, ainda mais, de quem exigir-se-á no plano internacional, como, por exemplo, pois objeto do trabalho em comento, o direito a um meio ambiente saudável.

Avançando, ainda sob a luz do conteúdo da Declaração Universal, preparam-se, em 1966, os Pactos das Nações Unidas sobre direitos civis e políticos, econômicos, sociais e culturais, já com força jurídica convencional. Em 1950 na Europa Comunitária, e em 1969 no quadro pan-americano, foram adotadas Convenções sobre os Direitos Humanos. 


\section{O SISTEMA INTERAMERICANO DE DIREITOS HUMANOS}

O movimento esboçado no final da Segunda Guerra Mundial, visando à proteção dos direitos do homem, teve imediato acolhimento nos países da América Latina, em cujos movimentos de independência as declarações dos Estados Unidos de 1776 e da Revolução Francesa de 1789 haviam exercido importante papel.

Pode-se dizer que a Declaração Interamericana se inspirou nos trabalhos preparatórios que culminariam na Declaração Universal e acrescentou, além de direitos, deveres internacionais do homem.

Os trabalhos que resultaram na Convenção de 1969 se arrastaram desde a elaboração do projeto de 1959 até a Conferência do Rio de Janeiro de 1965, quando se decidiu fosse esse projeto revisto pela Comissão Interamericana dos Direitos Humanos, e convocada conferência especializada. Não obstante os inúmeros obstáculos enfrentados, como a guerra do Vietnã, os regimes de exceção na Argentina, Peru e Brasil, e a decretação do estado de emergência no Chile, a Conferência reuniu-se em Costa Rica.

Diversas delegações, dentre elas a brasileira, tiveram ensejo de ressalvar a possibilidade de conflitos entre artigos da Convenção e disposições constitucionais. A Delegação dos Estados Unidos salientou as dificuldades de harmonizar as normas do common law com princípios baseados no direito romano. Apesar das dificuldades citadas, a Convenção foi assinada, e aceita a ideia da criação da Corte Interamericana de Direitos Humanos, sediada em São José da Costa Rica. Contudo, o Estado-parte da Convenção não é obrigado a reconhecer a jurisdição da Corte; caso queira, deve declarar expressamente tal reconhecimento.

Registra-se que os Estados Unidos da América não ratificaram a Convenção americana sobre direitos humanos. Argentina e México fizeram-no recentemente. Quanto ao Brasil, aderiu à Convenção em setembro de 1992 e, dez anos depois, reconheceu a competência obrigatória da Corte.

O sistema interamericano de proteção aos direitos humanos é composto por quatro diplomas normativos principais: 1) a Declaração Americana dos Direitos e Deveres do Homem, 2) a Carta da Organização dos Estados Americanos; 3) a Convenção Americana de Direitos Humanos; e 4) o Protocolo relativo aos direitos sociais, econômicos e culturais (San Salvador, 1988). Registra-se, por importante, que dessas normas internacionais há a obrigação genérica de respeito dos direitos humanos de todos sob a jurisdição dos Estados americanos.

A Convenção de San José designa, como órgãos competentes para conhecer dos 
assuntos relacionados ao cumprimento dos compromissos assumidos pelos Estados pactuantes, a Comissão Interamericana de Direitos Humanos e a Corte Interamericana de Direitos Humanos, que formam o Sistema Interamericano de Proteção dos Direitos Humanos.

Com efeito, o Sistema Interamericano de Proteção dos Direitos Humanos (SIPDH) é formado pela Comissão Interamericana de Direitos Humanos (Comissão ou CIDH) e pela Corte Interamericana de Direitos Humanos (Corte), órgãos especializados da Organização dos Estados Americanos, com atribuições fixadas pela Parte II da Convenção Americana de Direitos Humanos. Ambos são competentes para verificar o cumprimento, pelos Estados membros da Organização dos Estados Americanos (OEA), das obrigações assumidas com a assinatura da Convenção.

\subsection{A Comissão Interamericana de Direitos Humanos}

Prevista pelo artigo 112 da Carta da OEA, tem por função principal promover o respeito e a defesa dos direitos humanos e servir como órgão consultivo da OEA na matéria. A Carta ocupava-se da Comissão em apenas um artigo (art. 112), mas em 22 de novembro de 1969 foi aprovada em Costa Rica a Convenção Americana sobre Proteção dos Direitos Humanos, que veio complementar o citado dispositivo.

A Comissão atua como instância preliminar à jurisdição da Corte, possuindo amplo poder para requisitar informações e formular recomendações aos governos dos Estados pactuantes.

O verdadeiro ofício pré-jurisdicional da Comissão visa instaurar, contra um Estadoparte, por denúncia ou queixa - atinente à violação de regra expressa na área substantiva do Pacto - formulada (a) por qualquer pessoa ou grupo de pessoas; (b) por entidade não governamental em funcionamento regular; e (c) por outro Estado-parte; neste caso, porém, sob a condição de que o Estado denunciado haja reconhecido a competência da Comissão para equacionar essa forma original de confronto, com ou sem exigência de reciprocidade.

Em toda circunstância, o Pacto enuncia requisitos de admissibilidade da queixa, dentre os quais se destaca o esgotamento dos recursos proporcionados pela jurisdição interna. $\mathrm{O}$ processo ante a Comissão implica pedido de informações ao Estado sob acusação, com prazo certo, além de investigações várias, conduzindo afinal à lavratura de um relatório. Inoperantes que sejam as proposições ou recomendações, e esgotados os prazos razoáveis, pode a Comissão chegar àquele que parece ser o ponto culminante de sua competência pré-jurisdicional, ou seja, 
à publicação de suas conclusões sobre o caso concreto. Alternativamente, a Comissão tem qualidade para submeter a matéria à Corte Interamericana de Direitos Humanos.

\subsection{A Corte Interamericana de Direitos Humanos}

A Corte Interamericana não é acessível a pessoas ou a instituições privadas. Exauridas, sem sucesso, as potencialidades da Comissão, pode esta transferir o caso ao conhecimento do colégio judiciário. Debaixo de igual reserva, pode também fazê-lo outro Estado pactuante, mas desde que o país sob acusação tenha, a qualquer momento, reconhecido a competência da Corte para atuar em tal contexto - o do confronto interestatal à conta dos direitos humanos -, impondo ou não a condição de reciprocidade.

Órgão judiciário que é, a Corte não relata, propõe ou recomenda, mas profere sentenças, que o Pacto aponta como definitivas e inapeláveis. Declarando, na fundamentação do aresto, a ocorrência de violação de direito protegido pelo tratado, a Corte determina seja tal direito de pronto restaurado, e ordena, se for o caso, o pagamento de indenização justa à parte lesada. Nos relatórios anuais à Assembleia Geral da OEA, a Corte “...indicará os casos em que um Estado não tenha dado cumprimento a suas sentenças".

\section{O MEIO AMBIENTE SADIO COMO DIREITO HUMANO}

Ante o aumento considerável das agressões humanas ao meio ambiente, tanto no plano interno como no plano internacional, a afirmação de um direito ao meio ambiente sadio passa a ser condição para a sobrevivência da espécie humana. Não se pode olvidar que, pela natureza e extensão desse direito, este terá que obrigatoriamente ser tutelado, e com a maior brevidade possível, no plano internacional.

Com efeito, a preocupação mundial com a questão ambiental nos últimos anos tem proporcionado o reconhecimento crescente, nas ordens jurídicas nacional e internacional, de um direito humano específico a um meio ambiente equilibrado.

Os direitos enumerados na Declaração Universal de 1948 consagram duas formas: direitos civis e políticos e direitos econômicos, sociais e culturais. Há também os direitos coletivos, que seriam o direito ao ambiente sadio, o direito à paz, o direito ao desenvolvimento e o direito aos bens que constituem o patrimônio comum da humanidade.

Avançando, os direitos fundamentais de terceira dimensão, também chamados de 
direitos de solidariedade ou de fraternidade, possuem como característica serem direitos coletivos em sentido amplo. Estes não se destinam à proteção dos interesses individuais do homem, de um grupo ou de um determinado Estado, mas à proteção do gênero humano coletivamente considerado, caracterizando-se, por consequência, como direitos de titularidade difusa ou coletiva, tais como o direito de propriedade sobre o patrimônio comum da humanidade e o direito à autodeterminação dos povos tradicionais.

Dentre os direitos fundamentais chamados de terceira geração, destaca-se o direito ao meio ambiente sadio.

Deve-se a René Cassin (1947) a tese de que a proteção dos direitos humanos deveria ser ampliada, a fim de incluir o direito a meio ambiente equilibrado, isto é, livre de poluição, com o correspondente direito a água e ar puros. Norberto Bobbio ${ }^{3}$ afirma que o mais importante direito de terceira geração é o direito reivindicado pelos movimentos ecológicos, qual seja, o de viver num ambiente não poluído.

No âmbito interno, a Constituição Federal, inspirada nos documentos internacionais de proteção ao meio ambiente, inseriu o direito ao meio ambiente ecologicamente equilibrado na categoria de direito fundamental do homem em seu artigo 225. José Afonso da Silva ${ }^{4}$ ensina que, em face da Constituição vigente, o direito ao meio ambiente não pode ser mais considerado mero interesse difuso, mas forma de direito humano fundamental, dito de terceira geração.

O direito ao ambiente ecologicamente equilibrado está diretamente fulcrado no princípio da dignidade da pessoa humana, porque essencial à sadia qualidade de vida e à própria existência humana. Não há que se falar em dignidade humana se não houver condições bióticas e abióticas favoráveis ao bem-estar, à saúde e à vida humana, isto é, que proporcionem ao homem uma sadia qualidade de vida, a fim de que se possa afirmar a fundamentalidade do direito ao meio ambiente sadio.

Nesse contexto, o direito ao meio ambiente ecologicamente equilibrado está inserido no conceito de direito fundamental de terceira geração, conforme tem se posicionado o Supremo Tribunal Federal, ao considerar que tal direito contempla todo o gênero humano.

Com o fim da Segunda Guerra Mundial e o fim do nazismo, tem-se a emergência do processo de valorização da dignidade da pessoa humana e, por via de consequência, a

\footnotetext{
${ }^{3}$ BOBBIO, Norberto. A era dos direitos. Rio de Janeiro: Elsevier, 2004.

${ }^{4}$ SILVA, José Afonso da. Direito ambiental constitucional. 9. ed., São Paulo: Malheiros, 2011.
} 
reconstrução dos direitos humanos, como paradigma e referencial ético a orientar a ordem internacional.

Em que pese a visão inicial do direito internacional dos direitos humanos não se preocupar com o meio ambiente, após algum tempo, o crescente movimento de globalização, o desenvolvimento econômico e o avanço tecnológico, que culminaram com a degradação ambiental, ensejaram, a partir da década de 70, uma mudança de paradigmas na visão do homem, em especial, com a natureza. Acerca do conceito de globalização e sua dinâmica, Jacques Chevallier destaca:

\begin{abstract}
"Tendo continuidade depois da Segunda Guerra Mundial, o processo de internacionalização tomou uma nova dimensão ao longo dos anos 1990: o conceito de "globalização" traduziu uma aceleração e um aprofundamento desse processo; é a questão da pertinência mesmo do quadro estatal que está colocada a partir de agora. As fronteiras, físicas e simbólicas, que delimitavam a esfera de influência, o espaço de dominação do Estado, tornaram-se porosas: os Estados são atravessados por fluxos de todas as ordens, que eles são incapazes de controlar, de canalizar e, se necessário, conter; já não tendo controle sob as variantes essenciais que comandam o desenvolvimento econômico e social, a sua capacidade de regulação tornouse, concomitantemente, aleatória." 5
\end{abstract}

Francisco Rezek ${ }^{6}$ leciona que na administração de seu próprio território e em quanto faz ou deixa que se faça nos espaços comuns, o Estado subordina-se a normas convencionais, de elaboração recente e quase sempre multilateral, a propósito do meio ambiente. A gênese dessas normas justificou-se, antes de tudo, na interdependência: o dano ambiental devido à negligência ou à defeituosa política de determinado Estado tende de modo crescente a repercutir sobre outros, não raro sobre o inteiro conjunto, e todos têm a ganhar com algum planejamento comum. De outro lado essas normas prestigiam um daqueles direitos humanos de terceira geração, o direito a um meio ambiente saudável.

Hodiernamente, as normas ambientais no plano internacional constituem mais uma diretriz de comportamento que obrigações estritas de resultado. Esse fato vem sendo chamado de soft law.

Prosseguindo, a globalização do trato da matéria ambiental deu-se na Conferência das Nações Unidas sobre o Meio Ambiente, realizada em Estocolmo no ano de 1972. Dessa conferência resultaram dezenas de resoluções e recomendaçõe, às quais se soma a Declaração

\footnotetext{
${ }^{5}$ CHEVAlLIER, Jacques. O Estado pós-moderno. Belo Horizonte: Fórum, 2014, p. 18.

${ }^{6}$ REZEK, José Francisco. Direito internacional público: curso elementar. 14.ed. rev., aumen. e atual. São Paulo: Saraiva, 2013.
} 
de princípios que materializava as convicções comuns dos Estados participantes. Pode-se falar que o ideal da conjugação harmônica entre o desenvolvimento e a preservação ambiental foram os princípios basilares em Estocolmo ${ }^{7}$.

O regime de proteção internacional do meio ambiente tem, assim, sua origem não no direito dos tratados, mas em conferências internacionais e em documentos de soft law, uma vez que a questão ambiental não estava na pauta dos interesses político-econômicos dos Estados, mas era sim objeto das preocupações científicas com o futuro da humanidade.

Em atenção ao desenvolvimento aliado à preservação ambiental, 20 anos depois, ocorreu a Conferência das Nações Unidas sobre meio ambiente e desenvolvimento, realizada no Rio de Janeiro em junho de 1992.

Conciliando-se os dois valores, chega-se ao conceito de desenvolvimento sustentável: aquele que não sacrifica seu próprio cenário, aquele que não compromete suas próprias condições de durabilidade. Conforme ressalta Bernard Hours,

"Acontecimento maior, a cúpula da Terra no Rio, em 1992, representa o princípio batismal do desenvolvimento sustentável. Progresso econômico, justiça social, preservação do meio ambiente, pesam igualmente sobre o que nós cremos ainda no século XX. Em 1994 aparece o conceito de cidade sustentável. Em 1997 vê-se o aparecimento do Protocolo de Kioto, quando se confrontam os Estados a propósito do aquecimento do planeta e em 2002 culmina em Joanesburgo, sobre a proteção da biodiversidade. (...)

$\mathrm{Na}$ noção de desenvolvimento sustentável desenham-se duas afirmações principais de natureza diferente. A primeira sublinha a necessidade moral de preservar a qualidade do meio ambiente para preservar a qualidade de vida das gerações que virão. Se trata da solidariedade ao olhar da espécie humana. A segunda é de uma inspiração naturalista e em apelo à proteção da biodiversidade." (tradução livre, g.n.) ${ }^{8}$

Outrossim, a conexão entre as presentes e futuras gerações é enfatizada por Sachs, ao afirmar que "O conceito de desenvolvimento sustentável acrescenta uma outra dimensão - a sustentabilidade ambiental - à dimensão da sustentabilidade social. Ela é baseada no duplo imperativo ético de solidariedade sincrônica com a geração atual e de solidariedade diacrônica com as gerações futuras" $"$.

Nesse contexto, cabe aos Estados a responsabilidade maior pela busca do desenvolvimento preservacionista. Significa dizer que os executores principais desse novo

\footnotetext{
${ }^{7}$ LAGO, André Aranha Corrêa do. Estocolmo, Rio, Joanesburg:o Brasil e as três Conferências Ambientais das Nações Unidas. Brasília: Instituto Rio Branco, Fundação Alexandre de Gusmão, 2007.

${ }^{8}$ HOURS, Bernard. Développement, Gouvernance, Globalisation. Du XX au XXI Siècle. Paris, L'Harmattan, 2012, p. 54.

${ }_{9}^{9}$ SACHS, Ignacy. Desenvolvimento includente, sustentável, sustentado. Rio de Janeiro: Garamond, 2008.
} 
direito seguem sendo as personalidades originárias do direito das gentes. Não houve, por parte daquelas, uma abdicação que chame à frente da cena a comunidade científica ou as organizações não governamentais, embora seja este, provavelmente, o domínio de que mais intensamente participam esses atores privados, em um dos domínios de maior interesse da opinião pública.

As responsabilidades estatais são diferenciadas em função dos recursos de cada Estado, do seu grau de desenvolvimento, do seu patrimônio ecológico, do seu potencial poluente. Os textos do Rio de Janeiro destacam os deveres de prevenção, de precaução e de cooperação internacional, e enfatizam os direitos das gerações futuras, que não deveriam ser sacrificados em favor de um desenvolvimento a qualquer preço neste momento da história.

Para Paulo Affonso Leme Machado, desenvolvimento sustentável é uma locução verbal em que se ligam dois conceitos ${ }^{10}$. O conceito de sustentabilidade passa a qualificar ou caracterizar o desenvolvimento. Também nesse sentido, Pochmann alerta:

"O imperioso compromisso com o desenvolvimento nacional requer o planejamento de médio e longo prazo. Para isso, a nação precisa democraticamente se colocar de acordo com a convergência política capaz de permitir a construção das estratégias do amanhã que devem abarcar todos os brasileiros, sendo sobretudo compatíveis com a sustentabilidade ambiental e o avanço tecnológico da nação" 11 .

Segundo Fúlvio Eduardo Fonseca ${ }^{12}$, o processo de internacionalização da proteção do meio ambiente pode ser dividido em três fases: a) uma fase anterior à Conferência sobre Meio Ambiente Humano de 1972, marcada pelo surgimento dos diversos movimentos preservacionistas e a conscientização global do problema ambiental; b) uma segunda fase que compreende o período entre a Conferência de Estocolmo de 1972 e a Conferência do Rio de Janeiro sobre Meio Ambiente e Desenvolvimento de 1992, caracterizada pela preocupação setorial e fracionada do meio ambiente, com tratados específicos de proteção do mar, flora, fauna e ar; c) uma terceira fase, cujo marco temporal é a Conferência do Rio sobre Meio Ambiente e Desenvolvimento aos dias atuais, marcada pela proteção transetorial do meio

10 MACHADO, Paulo Affonso Leme. Direito Ambiental Brasileiro. 24a , ed., rev., ampl., e atual. São Paulo: Malheiros, 2016.

${ }^{11}$ POCHMANN, Márcio. Qual desenvolvimento? Oportunidades e dificuldades do Brasil contemporâneo. $1^{\mathrm{a}}$ ed. São Paulo: Publisher Brasil, 2009, p. 79.

12 FONSECA, Fúlvio Eduardo. A Convergência entre a proteção ambiental e a proteção da pessoa humana no âmbito do direito internacional. Revista Brasileira de Política Internacional, Brasília, v. 50, n.1, jan./jun. 2007. Disponível

http://www.scielo.br/scielo.phpscript=sci_arttex\&pid=S003473292007000100007\&Ing=en\&nrm=isso>. Acesso em 10/09/16. 
ambiente e novas modalidades de governança ambiental. No mesmo sentido, Mazzuoli e Teixeira concluem que:

"A globalização da proteção do meio ambiente exige, portanto, uma maior compreensão dos mecanismos de proteção aos direitos humanos. Dessa forma, a Assembleia Geral (Resolução n. 37/189A, de 1982) e a Comissão de Direitos Humanos da ONU (Resoluções n. 1982/7, de 1982, e 1983/43, de 1983), ao analisarem o alcance do Pacto dos Direitos Civis e Políticos das Nações Unidas, consolidaram o entendimento de que o direito à vida engloba o exercício pleno dos direitos civis políticos, econômicos, sociais e culturais a todos os indivíduos, povos, etnias, coletividades e grupos humanos. Nessa perspectiva, o direito ao acesso ao meio ambiente sadio se consolida como extensão do direito à vida."13

E citando o magistério de Cançado Trindade, tais autores observam que a conexão entre direitos humanos e meio ambiente ocorreu em um processo de transição da fase "da internacionalização da proteção ambiental”, em que a ênfase residia nas áreas de competência territorial dos Estados e suas fronteiras, para a fase da globalização, na qual "os princípios de caráter global aplicam-se aos territórios dos Estados, independente de qualquer efeito transfronteiriço, e regem zonas que não estão sob a competência de nenhum território nacional"14.

\section{INSTRUMENTOS NORMATIVOS PREVISTOS NO PLANO INTERNACIONAL}

Dentre os instrumentos normativos previstos no plano internacional, dada sua pertinência ao tema deste estudo, falar-se-á sobre: a Convenção Interamericana de Direitos Humanos (Pacto de San José da Costa Rica), o Protocolo de San Salvador e a Declaração de Estocolmo.

\subsection{Convenção Interamericana de Direitos Humanos (Pacto de San José da} Costa Rica)

A Convenção Interamericana sobre Direitos Humanos foi concluída em San José da Costa Rica, em 22 de novembro de 1969. À conclusão, doze Estados firmaram o texto. Sua

\footnotetext{
13 MAZZUOLI, Valério de Oliveira. TEIXEIRA, Gustavo de Faria Moreira. O Direito Internacional do Meio Ambiente e o Greening da Convenção Americana sobre Direitos Humanos. Revista Direito GV, São Paulo, jan-jun 2013, pp. 199-242.

14 CANÇADO TRINDADE, A.A. Direitos Humanos e Meio-Ambiente: Paralelo dos sistemas de proteção internacional. 1.ed. Porto Alegre: Sergio Antonio Fabris Editor, 1993.
} 
entrada em vigor sobreveio em 18 de julho de 1978, e o número de partes mediante ratificação ou adesão contava vinte e cinco repúblicas americanas no início de 2005. Diversas ratificações comportaram reservas. Nos termos de seu art. 74, $\S 1^{\circ}$, o Pacto de San José da Costa Rica se encontra aberto, sem limite no tempo, à adesão de todos os membros da Organização dos Estados Americanos.

\subsection{Protocolo de San Salvador}

O Protocolo de San Salvador foi assinado em 17 de novembro de 1988 e entrou oficialmente em vigor após a obtenção do número mínimo de ratificações, em 1999. Foi criado com a missão de suprir as necessidades do Pacto de San José da Costa Rica no que tange aos direitos econômicos, sociais e culturais.

Trata de temas como direito do trabalho, direitos sindicais (inclusive direito à greve), direito à previdência social, direito à saúde, direito a um meio ambiente sadio (art. 11), direito à alimentação, direito à educação, direito aos benefícios da cultura, direito à constituição e proteção da família, direito da criança, proteção de pessoas idosas, proteção de deficientes. Também traz relevantes mecanismos de proteção para os direitos assegurados, como a elaboração de relatórios pelos Estados.

\subsection{A Declaração de Estocolmo}

Foi a primeira Convenção mundial das Nações Unidas, juntamente com os Estados e a comunidade científica, sobre o Homem e o Meio Ambiente, visando a amenizar a problemática: homem versus natureza. Esse evento ocorreu nos dias 5 a 16 de junho do ano de 1972, na capital sueca, Estocolmo.

O escopo da supracitada referência era alertar o mundo para a necessidade de um critério e de princípios comuns que ofereçam aos povos do mundo inspiração e guia para preservar e melhorar o meio ambiente humano.

No âmbito da Conferência, foi realçada a existência de um conflito diplomático entre países desenvolvidos e países em desenvolvimento. Os primeiros, responsáveis pela maior poluição global, dispostos a encontrar uma solução conjunta para a conservação do meio ambiente. Os segundos, desinteressados na adoção de medidas que poderiam limitar seu potencial de desenvolvimento econômico, sem considerar os problemas ambientais que referido 
desenvolvimento provoca, os quais já eram conhecidos pelos países desenvolvidos.

Na referida Conferência de 1972 sobre o meio ambiente, o Brasil teve ensejo de salientar a importância do desenvolvimento dentro do contexto ambiental, tanto assim que a Declaração de Estocolmo, em seu preâmbulo, reconhece que "nos países em desenvolvimento a maioria dos problemas ambientais é causada pelo subdesenvolvimento. Milhões continuam a viver abaixo dos níveis mínimos necessários para uma existência humana, privados de comida, vestimenta, abrigo, educação e saúde".

\section{O DIREITO AO MEIO AMBIENTE SADIO E O GREENING DOS MECANISMOS DE PROTEÇÃO}

O ideal da Declaração Universal dos Direitos Humanos (1948), que englobou os direitos civis, políticos, econômicos, sociais e culturais, frise-se, sem que houvesse distinção significativa entre eles, corrobora a afirmação da indivisibilidade dos direitos humanos.

Atualmente, a indivisibilidade dos direitos humanos orienta a interpretação de sua aplicabilidade, que deve ser vista apenas como vetor de explicação da evolução do rol de direitos protegidos, não podendo a divisão em grupos, ou "gerações", ser utilizada para enfraquecer a proteção de determinada espécie de direito. De fato, após as duas Conferências Mundiais da Organização das Nações Unidas sobre Direitos Humanos (Teerã, 1968; Viena, 1993), observa-se a aceitação, pelos Estados, da chamada indivisibilidade e interdependência do conjunto, conduzindo à compreensão integral dos direitos humanos.

Soma-se ao exposto que a crescente poluição transfronteiriça e o aumento significativo no número de tragédias ambientais a partir da década de 1960 alertou a comunidade internacional para a necessidade de tratar o meio ambiente de forma ampla e não desvinculada de questões sociais e econômicas.

Nesse diapasão, Fritjof Capra ${ }^{15}$ ressalta que a busca de um crescimento econômico contínuo e indiferenciado é claramente insustentável, pois a extensão ilimitada num planeta finito só pode levar à catástrofe.

No que tange ao direito humano ao meio ambiente equilibrado, embora encontre previsão específica no art. 11 do Protocolo de San Salvador, observa-se que tal normativo não se apresenta suficiente para garantir a inocorrência de violações, já que somente os direitos

\footnotetext{
${ }^{15}$ CAPRA, Fritjof. O Ponto de Mutação: a ciência, a sociedade e a cultura emergente (trad. Álvaro Cabral). São
} Paulo: Editora Cultrix, 1982. 
civis, políticos, econômicos, sociais e culturais estão abrangidos pelos mecanismos de proteção da ONU e sistemas regionais de direitos humanos.

Isso não significa, em absoluto, que os casos envolvendo afrontas ao direito ao meio ambiente sadio não possam ser objeto de apreciação pelo Sistema Interamericano, mas sim que se faz necessário atentar-se para os instrumentos interpretativos a serem utilizados para que tais casos sejam admitidos.

De fato, conforme bem destacado por Mazzuoli e Teixeira, os direitos de solidariedade definidos pela Declaração de Estocolmo de 1972 - como o acesso ao meio ambiente sadio - quando interpretados como forma de exercício de uma série de direitos individuais e coletivos, passam a ser plenamente reivindicáveis.

Trata-se da denominada técnica de proteção ambiental pela via reflexa (ou "por ricochete"), baseada na concepção de que dentro da estrutura do atual direito internacional do meio ambiente a proteção da biosfera mostra-se eficaz por intermédio da indireta, porém, necessária proteção dos seres humanos. Prosseguem Mazzuoli e Teixeira esclarecendo que:

[...] $\mathrm{Na}$ dimensão coletiva da proteção ambiental, o meio ambiente humano transforma-se em bem comum, resultado do esverdeamento dos direitos econômicos, sociais e culturais. Tal dimensão tem implicado a tendência de se proteger grupos e coletividades em estado de vulnerabilidade decorrente da degradação ambiental."

(...) Assim, para que questões de cunho ambiental sejam submetidas ao sistema interamericano, é preciso socorrer-se ao chamado greening ou "esverdeamento" - fenômeno que ocorre quando se tenta (e se consegue) proteger direitos de cunho ambiental nos sistemas regionais de direitos humanos, que são sistemas aptos (em princípio) a receber queixas ou petições que contenham denúncias de violação a direitos civis e políticos. O que fazer então? Há técnicas e estratégias para que se submeta, com sucesso, uma questão ambiental no sistema regional interamericano, quando então se diz que o sistema "esverdeou-se"16.

Tendo em vista que o direito internacional do meio ambiente e os respectivos diplomas legais não ostentam mecanismos suficientemente vinculantes, aptos a garantirem sua proteção, seja no âmbito da ONU ou de outros organismos, o chamado "esverdeamento" do Sistema Interamericano, assim como dos demais sistemas regionais, tem sido considerado como uma das formas adequadas de buscar conferir-se eficácia ao direito humano ao meio ambiente equilibrado.

${ }^{16}$ MAZZUOLI, Valério de Oliveira. TEIXEIRA, Gustavo de Faria Moreira. O Direito Internacional do Meio Ambiente e o Greening da Convenção Americana sobre Direitos Humanos. Revista Direito GV, São Paulo, jan-jun 2013, pp. 208-210. 


\section{ANÁLISE DE PRECEDENTES DO SISTEMA INTERAMERICANO ENVOLVENDO DIREITOS HUMANOS E MEIO AMBIENTE}

Ao se ressaltar, especificamente, a previsão do direito ao meio ambiente sadio como direito humano, trata-se de tema que recebe diferentes enfoques conforme os instrumentos normativos analisados. Nesse sentido, observa-se que no art. $26^{17}$ da Convenção Americana sobre Direitos Humanos ("Pacto de San Jose da Costa Rica") que versa sobre desenvolvimento progressivo, a proteção aos recursos naturais surge como um dever vinculado aos direitos econômicos, sociais e culturais, ostentando, de certa forma, um caráter instrumental. Já no Protocolo Adicional à Convenção Americana sobre Direitos Humanos em Matéria de Direitos Econômicos, Sociais, e Culturais ("Protocolo de "San Salvador"), o meio ambiente é expressamente referido (art. 11) e reconhecido como direito humano ${ }^{18}$.

No âmbito do Sistema Interamericano de Direitos Humanos, a análise de eventuais violações tem seguido distintos parâmetros. Com efeito, segundo observa Thalita Lopes Motta, "Visualizam-se, por conseguinte, duas linhas de análise da interconexão entre direitos humanos e meio ambiente: a primeira se destina ao estudo da proteção ambiental conjugada a outros direitos; a segunda parece consagrar o bem jurídico ambiental de per si, em homenagem à promoção de políticas públicas ambientais e à proibição de degradação dos elementos naturais."

Quanto à primeira perspectiva analítica, a ideia de base é que o direito ao meio ambiente sadio constitui uma pré-condição para o gozo e garantia de outros direitos humanos. Nesse sentido, o festejado doutrinador Cançado Trindade evidenciava, de forma pioneira, a conexão entre o direito internacional dos direitos humanos e o direito ao meio ambiente equilibrado, lecionando que este se configurava como extensão do direito a uma vida digna, ao mesmo tempo que destacava a ampliação interpretativa das Cortes Regionais quanto à análise dos conteúdo dos direitos fundamentais.

De outro lado, aqueles que conferem autonomia ao direito humano ao meio ambiente, com base no art. 11 do Protocolo de San Salvador, consideram possível submeter-se

\footnotetext{
${ }^{17}$ Artigo 26. Desenvolvimento progressivo: Os Estados-Partes comprometem-se a adotar providências, tanto no âmbito interno como mediante cooperação internacional, especialmente econômica e técnica, a fim de conseguir progressivamente a plena efetividade dos direitos que decorrem das normas econômicas, sociais e sobre educação, ciência e cultura, constantes da Carta da Organização dos Estados Americanos, reformada pelo Protocolo de Buenos Aires, na medida dos recursos disponíveis, por via legislativa ou por outros meios apropriados.

${ }^{18}$ Art.11. Direito a um meio ambiente sadio: 1. Toda pessoa tem direito a viver em meio ambiente sadio e a contar com os serviços públicos básicos. 2. Os Estados-Partes promoverão a proteção, preservação e melhoramento do meio ambiente.
} 
casos de violação direta a esse direito, sem a necessidade de evocar-se violações a outros direitos humanos como suporte jurídico para admissibilidade e análise de tais pleitos.

Nesse contexto, cumpre destacar que a existência de precedentes do SIDH relativos à temática da proteção ambiental encontra-se diretamente ligada à questão dos limites à justiciabilidade dos direitos econômicos, sociais e culturais, no âmbito da Comissão e da Corte. Isto porque, ao analisarem-se as decisões desta, observa-se que as violações ao direito humano ao meio ambiente têm sido reconhecidas de forma indireta e subsidiária à violação dos direitos civis e políticos, através do mecanismo de greening, consoante mencionado anteriormente.

$\mathrm{Na}$ esfera da Corte Interamericana, o primeiro caso em que foi abordada a temática ambiental, embora de forma indireta, foi o que versou sobre a concessão irregular de exploração madeireira em terras indígenas, na Comunidade Awas Tingni Mayagna (Sumo) vs. Nicarágua (Sentença de 31 de agosto de 2001. Série C, n. 79). Posteriormente, a Corte ainda apreciou questões de direitos humanos envolvendo matéria ambiental, também de modo incidental, nos casos Comunidade N'djuka Maroon, de Moiwana, em Moiwana vs. Suriname (Sentença de 15 de junho de 2005. Série C, n. 124, parágrafo 86); Comunidade Indígena Yakye Axa vs. Paraguai (Sentença de 17 de junho de 2005. Série C, n. 125); Comunidade Indígena Sawhoyamaxa vs. Paraguai (Sentença de 29 de março de 2006. Série C, n. 146); Caso Comunidad Saramaka vs. Suriname (Sentença de 28 de novembro de 2007. Série C, n. 172), entre outros.

Um dos aspectos a destacar, na análise da jurisprudência da Corte IDH, em especial nos casos acima citados, é que as violações ao direito ao meio ambiente sadio foram apreciadas à luz da garantia do direito de comunidades indígenas e tribais a suas terras, em especial sob o enfoque do direito à vida digna e à propriedade. No caso Comunidad Saramaka vs. Suriname, por exemplo, em que houve a concessão das terras tradicionais a empresas de mineração e madeira, sem que o Estado promovesse a necessária e prévia informação, a Corte IDH considerou que os povos tribais e indígenas possuem o direito "de serem titulares dos recursos naturais que utilizaram tradicionalmente dentro de seu território pelas mesmas razões pelas quais têm o direito de serem titulares da terra que usaram e ocuparam durante séculos. Do contrário, a sobrevivência econômica, social e cultural destes povos está em risco." (Corte IDH. Caso del Pueblo Saramaka vs. Suriname. Sentença de 28 de novembro de 2007. Série C $\mathrm{n}^{\mathrm{o}}$. 172, parágrafo 121).

Há, porém, alguns precedentes que apontam para uma ampliação da perspectiva de análise da Corte Interamericana, na medida em que o exame das violações ao direito ao meio 
ambiente equilibrado não foi vinculado a direitos territoriais de comunidades étnicas, mas a direitos humanos de outra ordem. Nesse sentido, um dos casos que merecem destaque é o Caso Claude Reyes e outros vs. Chile (Corte I.D.H., Caso Claude Reyes y otros. Sentença de 19 de setembro de 2006. Série C n. 151), no qual o Tribunal reconheceu ter havido violação ao art. $8^{\circ}$ da Convenção Interamericana de Direitos Humanos, diante da ausência de efetividade de um procedimento administrativo (recusa de um órgão do Estado chileno em prestar informações sobre um projeto de exploração florestal de grande impacto).

Outro caso em que o tema ambiental foi trazido ao debate, ainda que lateralmente, foi o Caso Kawas Fernández vs. Honduras (Corte I.D.H., Caso Kawas Fernández vs. Honduras. Sentença de 3 de abril de 2009. Série C No 196), em que foi examinado o assassinato de uma militante da causa ambiental e as falhas decorrentes da desídia na apuração estatal dos fatos, tendo sido reconhecido, no curso do processo, que os defensores hondurenhos do meio ambiente viviam em constante perigo. Tais decisões revestem-se de importância, porquanto embora o aspecto ambiental não tenha sido examinado em sua especificidade, pode-se observar um esforço da Corte Interamericana em não restringir a análise do direito ao meio ambiente somente a violações envolvendo direitos de comunidades protegidas, a exemplo do que ocorre na Corte Europeia de Direitos Humanos.

De outro lado, no âmbito da Comissão Interamericana, interessante citar-se um precedente histórico, qual seja, o pronunciamento em que analisou o confronto entre as políticas de desenvolvimento fomentadas à época pelo Estado do Amazonas e o então Território de Roraima e a cultura do povo indígena Yanomami, havendo, contudo, aquele órgão se limitado a recomendar ao Brasil a demarcação da reserva indígena em questão, pois o Estado brasileiro ainda não havia aceito a jurisdição da Corte (CIDH, Resolução n. 12/85, Caso 7615, Brasil, 5 de março de 1985).

De relevo cita-se, outrossim, dois Relatórios de Admissibilidade da Comissão em casos envolvendo a ocorrência de danos ambientais no Peru, por contaminações causadas por um complexo metalúrgico (Caso La Oroya ${ }^{19}$ ) e por um depósito de resíduos sólidos (Comunidad San Mateo Huanchor ${ }^{20}$ ), em áreas de pequenos vilarejos, onde os moradores não integravam comunidades indígenas ou tribais, razão pela qual constituem um marco quanto às possibilidades de garantia do direito humano ao meio ambiente sadio a populações que não

\footnotetext{
${ }^{19}$ CIDH. Informe no 76/09. Admisibilidade. Comunidad de la Oroya (Perú). 5 de agosto de 2009.

${ }^{20}$ CIDH. Informe $n^{\circ}$ 69/04. Petición 504/03. Admisibilidad. Comunidad San Mateo de Huanchor y sus miembros (Perú). 15 de outubro de 2004.
} 
integram um grupo especialmente protegido.

Por fim, um dos casos de maior relevância na temática ambiental analisado pela Comissão Interamericana é o que envolveu a construção do mega empreendimento da usina hidrelétrica de Belo Monte, em Altamira, no Estado do Pará, em que a Comissão, em abril de 2011, dado o grave risco de danos irreparáveis às comunidades do Rio Xingu, decretou medidas cautelares em favor dos atingidos, ordenando ao Estado brasileiro uma série de providências para proteção da vida e integridade dos membros daquelas comunidades, dentre as quais a de promover sua consulta prévia e informada; garantir-lhes o prévio acesso ao Estudo de Impacto Social e Ambiental do projeto; proteger a vida dos povos em isolamento voluntário, além de suspender o processo de licenciamento da UHE Belo Monte (CIDH. MC 382/10 Comunidades Indígenas da Bacia do Rio Xingu, Pará, Brasil, de $1^{\text {o }}$ de abril de 2011).

Neste caso, contudo, a expressiva dificuldade de implementação e cumprimento das medidas decretadas pela Comissão, em face da postura de resistência adotada pelo Brasil, exemplifica os enormes desafios para promoção da interconexão entre os direitos humanos e o direito ao meio ambiente equilibrado, bem como evidenciam a imperiosa necessidade de avançar-se em mecanismos que possam garantir maior efetividade ao funcionamento do Sistema Interamericano na proteção desses direitos.

\section{CONCLUSÕES}

Do panorama traçado a partir da análise histórica, assim como das particularidades e casos concretos envolvendo o direito ao meio ambiente sadio e os direitos humanos apreciados no âmbito do Sistema Interamericano de Direitos Humanos, é possível concluir-se que a interconexão de tais direitos apresenta-se indiscutível, sendo cada vez mais acionada em diferentes demandas, a fim de viabilizar seu exame conjunto, ainda que por via indireta ou secundária, concorrendo para conferir maior expansão às normas de proteção.

Com efeito, dos diversos casos concretos abordados, observa-se que tem sido adotada uma linha de interpretação ampliativa dos direitos à vida digna, à integridade física, à liberdade de expressão, ao acesso à justiça, entre outros, conferindo-se ênfase ao direito ao meio ambiente equilibrado como fundamental à dignidade da pessoa humana, o que certamente contribuirá para aumentar as garantias aos direitos humanos de forma geral.

Contudo, considera-se que inúmeros desafios estão por serem enfrentados nessa temática, na medida em que é preciso superar a noção antropocêntrica que ainda prevalece em 
alguns foruns de decisão, na qual o direito ao meio ambiente é visto sob a ótica individual e não como um direito difuso, o que termina por restringir o âmbito das reparação das violações a vítimas determinadas e, por consequência, a própria noção de proteção a um direito que é de toda a coletividade.

Por fim, e na mesma medida, há que se evoluir, em especial no Sistema Interamericano de Direitos Humanos, para conferir ao direito humano ao meio ambiente sadio o mesmo protagonismo de que gozam os direitos civis, políticos, econômicos, sociais e culturais, de forma que suas violações possam ser analisadas, pela Comissão e pela Corte, de maneira direita, e não apenas através de mecanismos reflexos, contribuindo assim para um avanço nos instrumentos interpretativos que conduza à maior efetividade da proteção ao meio ambiente e à vida digna do ser humano, tanto nas Américas quanto no planeta.

\section{REFERÊNCIAS}

ACCIOLY, Hildebrando; SILVA, G. E. do Nascimento; CASELLA, Paulo Borba. Manual de direito internacional público, 21ed. - São Paulo: Saraiva, 2014.

BONAVIDES, Paulo. Curso de direito constitucional. 22. Ed. - São Paulo: Malheiros, 2008.

BOBBIO, Norberto. A era dos direitos. - Rio de Janeiro: Elsevier, 2004.

BOSSELVAN, Klaus. Direito humanos, meio ambiente e sustentabilidade. In: SARLET, Ingo Wolfgang (Org.). Estado socioambiental e direitos fundamentais. - Porto Alegre: Livraria do Advogado, 2010.

BRASIL, Constituição da República Federativa do Brasil de 05 de outubro de 1988. Disponível em: http://www.planalto.gov.br. Acesso em 10/05/16.

BRASIL, Decreto 4.463, de 8 de novembro de 2002, que promulga a declaração de reconhecimento da competência obrigatória da Corte Interamericana de Direitos Humanos, sob reserva de reciprocidade, conforme art. 62, da Convenção de 1969. Disponível em: http://www.planalto.gov.br/ccivil_03/decreto/2002/d4463.htm. Acesso em 09/05/16.

BRASIL, Promulga o Acordo sobre cooperação em Matéria Ambiental, celebrado entre o Governo da República Federativa do Brasil e o Governo da República oriental do Uruguai, em Montevidéu, em 28 de dezembro de 1992. Disponível em: http://www.planalto.gov.br/ccivil_03/decreto/1997/D2241.htm. Acesso em 10/05/16.

BRASIL, Convenção Americana de Direitos Humanos. Disponível em: http://www.planalto.gov.br/ccivil_03/decreto/D0678.htm. Acesso em 09/05/16. 
BRASIL, Protocolo de San Salvador. Disponível em: http://www.cidh.org/Basicos/Portugues/e.Protocolo_de_San_Salvador.htm. Acesso em 09/05/16.

BRASIL. Supremo Tribunal Federal. http://redir.stf.jus.br/paginadorpub/paginador.jsp?docTP=AC\&docID=387260. Acesso em: 10/05/16.

Comissão IDH. Resolução n. 12/85. Caso 7615, Brasil, 5 de março de 1985.

Comissão IDH. Informe n. 69/04. Petição 504/03. Admissibilidade. Comunidad de San Mateo de Huanchor y sus miembros. Peru, 15 de outubro de 2004.

Comissão IDH. Informe $\mathrm{n}^{\mathrm{o}}$ 76/09. Admisibilidade. Comunidad de la Oroya. Peru, 5 de agosto de 2009.

Comissão IDH. MC 382/10. Comunidades Indígenas da Bacia do Rio Xingu, Pará, Brasil, de $1^{\circ}$ de abril de 2011 .

Corte IDH. Caso Comunidad Awas Tingni Mayagna (Sumo) vs. Nicarágua. Sentença de 31 de agosto de 2001. Série C, n. 79.

Corte IDH. Caso Moiwana vs. Suriname. Sentença de 15 de junho de 2005. Série C, n. 124, parágrafo 86.

Corte IDH. Caso Comunidad Indígena Yakye Axa vs. Paraguai. Sentença de 17 de junho de 2005. Série C, n. 125.

Corte IDH. Caso Comunidad Indígena Sawhoyamaxa vs. Paraguai. Sentença de 29 de março de 2006. Série C, n. 146. 151.

Corte IDH. Caso Claude Reyes y otros. Sentença de 19 de setembro de 2006. Série C, n.

Corte IDH. Caso Pueblo Saramaka vs Suriname. Sentença de 28 de novembro de 2007. Série C, n. 172.

Corte IDH. Caso Kawas Fernández vs. Honduras. Sentença de 3 de abril de 2009. Série C, n. 196.

CANÇADO TRINDADE, A.A. Direitos Humanos e Meio-Ambiente: Paralelo dos sistemas de proteção internacional. 1.ed. Porto Alegre: Sergio Antonio Fabris Editor, 1993.

CHEVALLIER, Jacques. O Estado pós-moderno. Belo Horizonte: Fórum, 2014.

DUPUY, Pierre-Marie. Droit international public. 5.ed. Paris: Dalloz, 2000. 
FONSECA, Fúlvio Eduardo. A Convergência entre a proteção ambiental e a proteção da pessoa humana no âmbito do direito internacional. Revista Brasileira de Política Internacional, Brasília, v. 50, n.1, jan./jun. 2007. Disponível em: http://www.scielo.br/scielo.phpscript=sci_arttex\&pid=S003473292007000100007\&Ing=en\&nr $\mathrm{m}=$ isso. Acesso em 10/05/16.

FOSTER, John Bellamy. A ecologia em Marx: materialismo e natureza. Rio de Janeiro: Civilização Brasileira, 2005.

HOURS, Bernard. Développement, Gouvernance, Globalisation. Du XX au XXI Siècle. Paris, L'Harmattan, 2012.

MACHADO, Paulo Affonso Leme. Direito Ambiental Brasileiro. 24a, ed., rev., ampl., e atual. São Paulo: Malheiros, 2016.

MAZZUOLI, Valério de Oliveira. TEIXEIRA, Gustavo de Faria Moreira. O Direito Internacional do Meio Ambiente e o Greening da Convenção Americana sobre Direitos Humanos. Revista Direito GV, São Paulo, jan-jun 2013, p. 199-242.

MOTTA, Thalita Lopes. Um panorama jurisprudencial da proteção do direito humano ao meio ambiente ecologicamente equilibrado no Sistema Interamericano de Direitos Humanos. Revista Veredas do Direito, Belo Horizonte, v.6, n.12, p.9-24, Julho-Dezembro de 2009.

PIOVESAN, Flávia. Direitos Humanos e justiça internacional: um estudo comparativo dos sistemas regionais europeu, interamericano e africano. 2. Ed. - São Paulo: Saraiva, 2012.

POCHMANN, Márcio. Qual desenvolvimento? Oportunidades e dificuldades do Brasil contemporâneo. $1^{\text {a }}$ ed. São Paulo: Publisher Brasil, 2009.

RESENDE, Augusto César Leite de. A tutela jurisdicional do direito humano ao meio ambiente sadio perante a Corte Interamericana de direitos humanos. Belo Horizonte: Fórum, 2015.

REZEK, José Francisco. Direito internacional público: curso elementar. 14.ed. rev., aumen. e atual. - São Paulo: Saraiva, 2013.

SACHS, Ignacy. Desenvolvimento includente, sustentável, sustentado. Rio de Janeiro: Garamond, 2008.

SILVA, José Afonso da. Direito ambiental constitucional. 9. ed. - São Paulo: Malheiros, 2011. 